Proceedings of the 2011 Winter Simulation Conference

S. Jain, R.R. Creasey, J. Himmelspach, K.P. White, and M. Fu, eds.

\title{
BUSINESS PROCESS MODELING AND SIMULATION
}

\author{
Geoffrey Hook \\ Lanner Group \\ The Oaks, 5 Clews Road \\ Redditch. B98 7ST UK
}

\begin{abstract}
This paper investigates the development of simulation in relation to Business Process Modeling (BPM). Comparing the way discrete event simulation is used alongside BPM software as opposed to the more traditional use of simulation as a stand-alone technology more rooted within the Industrial Engineering and Operational (Operations) Research disciplines. The paper will compare the way simulation is supported within the two environments and propose how simulation for BPM can develop and become more successful. Particular focus will be placed on the way a business process is modeled and for what purpose the model is constructed. The topic of appropriate process data for simulation is not a major focus of this paper, although it is clearly a major topic in its own right. In this paper BPM is used as 'shorthand' for Business Process Modeling and not for Business Process Management which is its more popular contemporary usage.
\end{abstract}

\section{INTRODUCTION}

The objective of this paper is to provide suggestions to the Business Process Modeling (BPM) community as to how they can better utilize discrete event simulation to deliver real business value for their organizations and customers. There have been many papers and books written on how to conduct simulation projects, covering both the 'art' of model design and the statistics crucial for the valid use of data and for good experimental design. This paper will not go over those aspects but will draw upon how simulation has been applied in a 'pure play' form by Operational Researchers and Industrial Engineers and how the technique has been adopted by the Business Process Modeling community. The point of view developed in this paper is to a degree a personal reflection based upon my experience in discrete event simulation over a 30 year period. In particular drawing upon extensive simulation project work undertaken within the automotive industry during the early part of my career and the experience gained applying the technique across all sectors. The second major contributor being my experience collaborating with leading Business Process Modeling providers including IBM and Software AG (previously IDS Scheer) to incorporate simulation within their toolsets. The paper begins by introducing the background of Business Process Modeling, then covering the development of simulation technology independent to BPM before moving onto how simulation is used with BPM. Finally a number of observations and recommendations are provided to promote thinking amongst both providers of simulation aligned with BPM as well as potential users. 


\section{BUSINESS PROCESS MODELING}

Techniques to model business processes have been in existence in many forms since early in the 20th century. Basic flow charts have been traced back to the 1920's developing into more modern approaches such as IDEF in the 1970's and more recently UML (Unified Modeling Language) and latterly BPMN (Business Process Modeling Notation). The actual term Business Process Modeling (BPM) may have originated with S. Williams (1967), but it became more popular in the 1990's. BPM emerged as a structured approach, often extensively used in the support of software engineering, to describe a collection of related activities to deliver a desired goal. 'Process' thinking became the cornerstone of business improvement and drives for greater productivity in many organizations. Business Processes were sometimes categorized as Management, Operational or Support processes. The operational processes being those related to the core activity of the business in terms of manufacturing or providing a value-add service to customers. Around this time Business Process Re-engineering became popular through Michael Hammer \& James Champny's book "Reengineering the Corporation: A manifesto for Business Revolution", written in 1993. In 1984 Professor Scheer founded IDS Scheer AG; this took Business Process Modeling to the next level, substituting the ' $\mathrm{M}$ ' of modeling for that of management. Software AG have since acquired the IDS Scheer company. Although Scheer's approach included business process modeling he created a much more sophisticated methodology fully encompassing the strategy, design implementation and control of processes, including IT architecture, data and the organization that supports the business enterprise.

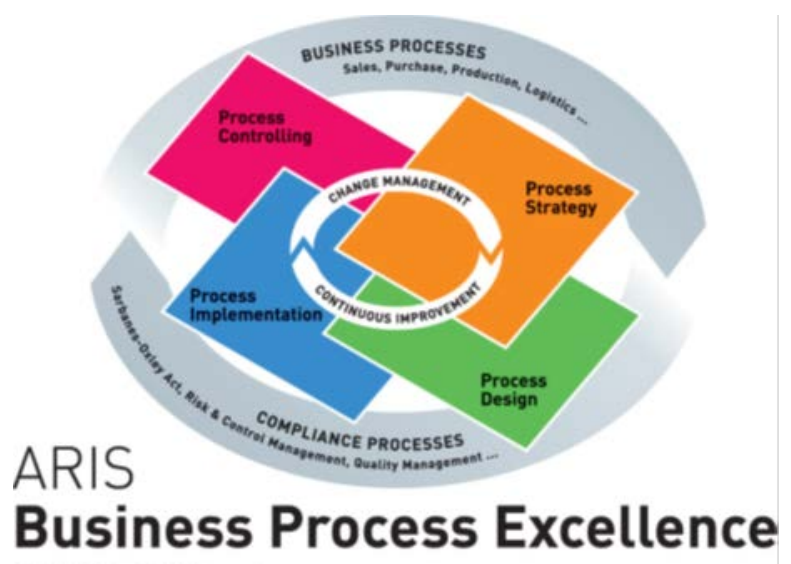

Core principles in business process modeling have always been the need to share and maintain process models across and between organizations without ambiguity; as such standards and methodologies have dominated the development of the discipline. These models also began as largely 'static pictures' with no intention of being executed in their native form. This aspect did change with the development of workflow engines and their integration into Business Process Management Suites. In my opinion the dominant influences on BPM have come from the IT side of the business, modeling processes for implementation in software. Business Process Management as an approach or philosophy rather than as purely software tools adopted simulation as a technology or optional component within the methodology. Many Business Process Management vendors (Software AG included) provide simulation functionality as an added component to their suites. The way simulation is supported by these toolsets varies widely, in terms of the capability provided and the way it is integrated and presented to users. How simulation appears in Business process modeling or management toolsets will be explored further in section 4. 


\section{SIMULATION}

My experience of simulation began as a student (1978) where we had to code a simulation model of a bus service on a circular route picking up and dropping passengers. In order to complete this assignment the students had to understand how to represent the system using events and how to manage a timeset of events so the simulation progressed. Discrete event simulation is where my personal experience has been gained and this simulation approach is the most widely used in simulating processes whether in manufacturing, service or administrative operations. Although simulation languages did exist at that time the students had to code this model in a programming language using 'punch cards', so no higher level objects or visualization was available to help them out. Simulation as a technology to support business decision making became more popular through the 1980's and 90's as software tools developed specifically for simulation. Much of the simulation work was undertaken by Operational researchers (often from a mathematics background) or industrial engineers. Simulation modeling was a serious exercise taking particular skills and significant time. The simulation model was specifically designed to address a particular business problem, whether that be in the automotive world looking at increasing throughput of facilities or designing passenger services at airports. On occasions these models were high level and simple, other applications required very detailed micro-level simulation models of systems. The model was dependent on the decision required, informing a decision between a number of strategic options or the proving of a manufacturing plant investment. Other data sources were used, e.g. CAD drawings, but only to provide information not as a basis for building the model. Simulation software developed at a rapid pace through this period with the introduction and rapid enhancement of products such as WITNESS by my own organization.

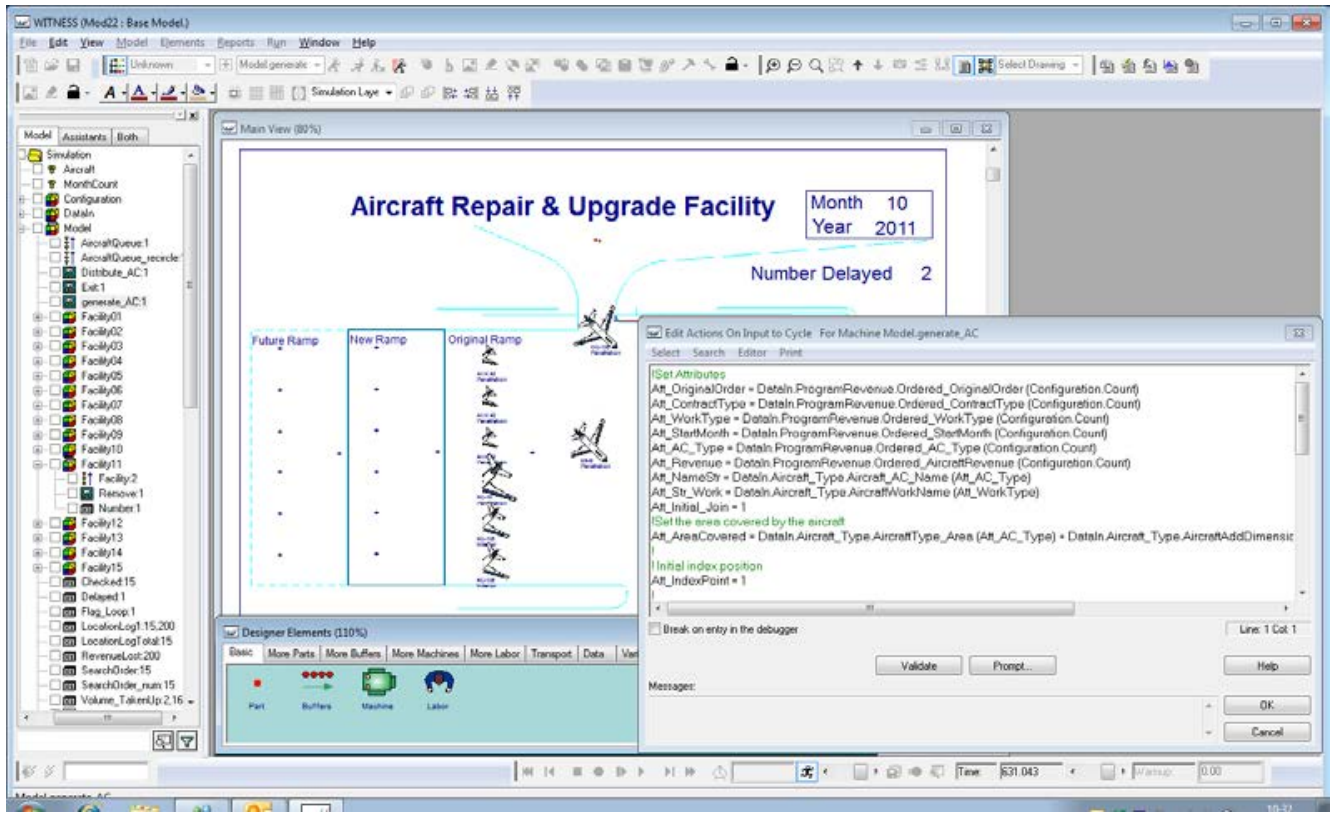

Figure 2: WITNESS illustrating high level objects and code capability

These simulators reduced the time to build models and reduced the chance of error by utilizing more sophisticated pre-built objects commonly required, i.e. activities, queues, resources and approaches for linking these together. The most successful simulation software packages had the right balance between these higher level objects and the ability to 'code' rules for routing, prioritization, resource allocation etc. as well as to handle data. Today these stand-alone simulators are commonly used throughout businesses in all sectors, they are also more widely accessible to users than the original code based tools. The re- 
quirement to be able to design the right model, the right data structures and experimentation to answer the particular business problem still remain as one of the biggest influencers on whether a simulation project is successful.

\section{SIMULATION OF BUSINESS PROCESS MODELS (BPM)}

The simulation of business process models which have previously been captured has an obvious attraction. Clearly simulation is a way of testing and measuring potential improvements to these process models before implementation, potentially saving costly mistakes and avoiding pilot projects where process changes are tested in the real world. Simulation is strongly recommended and identified as one of the ten 'must have' technologies for Business Process Management toolkits by the analyst firm Gartner. Many business process modeling and management suites now have simulation built in. In some cases the simulation capability is newly developed by the BPM tool vendors and in other cases it is based upon existing stand-alone simulation tools and integrated within the BPM software. Different BPM tools follow different methods, however each follows a standard approach, the most modern being the BPMN standard. The modeling software is there to provide an environment to model processes, maintain and share these models, it is not there to provide simulation. In these tools simulation is seen as an optional extra, often a desirable and strongly advocated optional extra. Business process models provide a static representation of the process being studied, simulation adds a dynamic component bringing the process to 'life' albeit still as a model. Additional information is required over and above that contained in the BPMs i.e. activity times, arrival information, resource availability and routing logic that can be executed within the simulation. This additional information is normally added to the BPMs using forms and stored in a proprietary manner often invisible from the process diagram. Some of this information is not always easily added, for example process modeling tools do not tend to have objects to represent queues and constraints for these queues, a second example is the overall control method that determines the routing or work prioritization, facilities to add this logic which has been a major part of the stand-alone simulation tools is usually not well addressed in the simulation provided for BPMs.

The role of simulation in the business process world should be similar to that in the manufacturing or supply chain operations, however often the BPMs that get simulated have been constructed for other reasons. As stated previously the BPMs are often created as part of a software development cycle or to publish the process to workers, they have not been designed to help answer a specific business question. If these models are used for simulation to address a question other than a simple validation of the process design they are likely to be the wrong models. A recent simulation project at Bank of America initially used existing business process models that had been developed to support a business rationalization project following a merger. These models were very detailed and the process was modeled as a hierarchy with upwards of 80 separate models. The business question to be addressed by simulation was to do with resourcing decisions and how to cope with a backlog of work. Clearly for this purpose a simpler model of the process could be used, a new model was developed using the detailed models as information, this leaner model containing aggregated activities made the simulation project much more efficient and effective.

Business Process Tools can be very detail oriented, given that these tools are likely to be 'owned' by IT or business analysts they are very suited towards the 'Design' and 'Implementation' steps of the project cycle shown below. Existing models may on the one hand be too detailed, similarly they may also be lacking. In that resources that support activities outside as well as those within the specific model being simulated may not be properly represented in terms of availability. Simulation has a big role in the 'Strategize' step where different business approaches might be compared prior to entering a detailed design phase. 


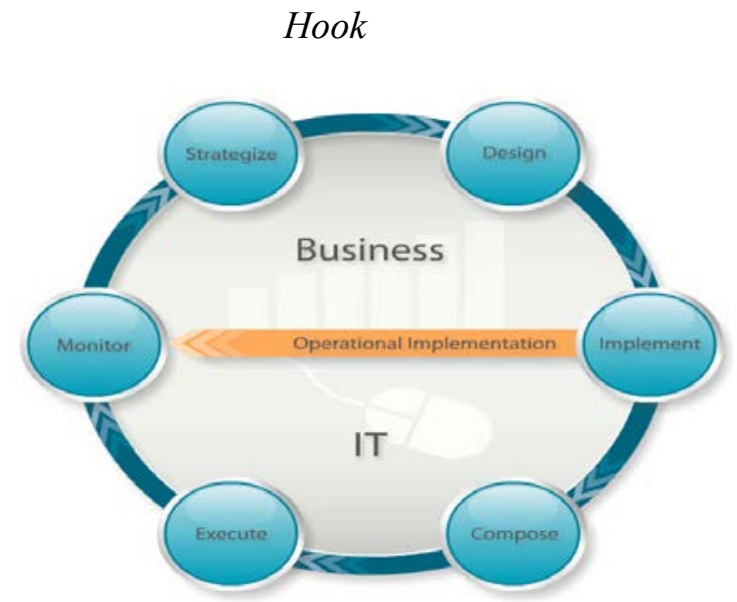

Figure 3 : Project Cycle - Software AG

The formal business process diagram method adopted by the toolset being used may not be the most effective modeling approach for a the basis of a simulation model in the strategize phase, a more flexible conceptual basis and richer graphical representation might be more appropriate. The formality of business process modeling is driven by a need for consistency and reuse across the enterprise, which of course is crucial in the mainstream business process diagramming activities.

\section{CONCLUSIONS}

In summary this paper recommends a number of guidelines for users of simulation provided by Business Process Modeling tools;

1. Be clear as to the question being addressed, and the focus of the simulation.

2. Make sure you have the 'right' model.

3. Develop the appropriate measures and targets for the simulation, after all you can't improve what you aren't measuring.

4. Simulation with little data still has value in terms of validating processes.

5. Determine a defined list of parameters and ranges that are under consideration and experiment accordingly.

6. Undertake sufficient experimentation and replications to be sure valid answers are obtained.

From the vendor or BPM software development perspective there should be a recognition that there are lessons to be learnt from the 'pure play' simulation software tools and that simulation in BPM is indeed in an 'early adopter' phase. The users of simulation within the BPM toolset are generally inexperienced with simulation analysis, this factor together with where process modeling as a technology is used by a business leads me to suggest a number of guidelines for the tool providers.

1. Provide support in the form of 'wizards' or 'templates' to steer the user in the specific analysis they want to undertake, process design validation, process improvement, optimization of resources etc. providing the appropriate reports etc.

2. Provide experimentation support to ensure robust results in terms run length or number of replications to ensure statistical validity.

3. Develop partnerships with 'pure play' simulation suppliers to benefit from that experience in the design of simulation capability and the opportunity to utilize a full simulation software product should that be more appropriate. 
Simulation of business process models being developed directly from process modeling tools and data is of great benefit to organizations. Implementation has some way still to go as the use of simulation in this environment matures.

\section{ACKNOWLEDGMENTS}

I would like to thank Mark Barnett of The Bank of America for his insight and being able to draw upon experience gained from one of his recent projects.

\section{REFERENCES}

Williams, S. 1967. "Business Process Modeling Improves Administrative Control," Automation, December, 1967, 44-50.

Hammer, M. and J. Champny. 1993. Reengineering the Corporation: A manifesto for Business Revolution.

\section{AUTHOR BIOGRAPHY}

GEOFFREY HOOK has worked in the field of Operational Research and Simulation for 30 years after graduating from the University of Warwick Business School and gaining an MSc in the Social Aspects of Science and Technology from the University of Aston in Birmingham. Geoff is one of the founders of the Lanner Group who specialize in simulation software and services, developing products such as WITNESS and L-SIM which is a simulation engine for BPMN integrated within a number of world leading Business Process Modeling solutions. At the Lanner Group he has held a number of senior positions in consulting as well as in new product and solution design. Geoff Hook is a member of the UK Operational Research Society and sits on the societies' Awards Committee including adjudicating on the Tocher award for the best simulation paper in the Journal of Simulation. He is also a member of the Warwick Business Schools’ MSc Course Advisory Board. His email address is ghook@lanner.com. 